\title{
ALLAN J. KUETHE y KENNETH J. ANDRIEN, The Spanish Atlantic World in the Eighteenth Century. War and the Bourbon Reforms, 1713-1796, Cambridge University Press, New York, 2014.
}

Desde la última década se viene produciendo un progreso en cuanto al número y calidad de publicaciones referidas al imperio español. La presente obra es un buen ejemplo de ello. Los dos autores, por tanto, son continuadores de una tradición que está bien consolidada en el panorama de la investigación.

Allan F. Kuethe, académico de la Real Academia de la Historia y de la Real Academia de Buenas Letras de Sevilla además de profesor de la Texas Tech University, ha trabajado en las reformas borbónicas centrándose en su impacto en el mundo colonial. En dos de sus más destacables publicaciones como han sido Military Reform and Society in New Granada, 1773-1808 (1978) y Cuba, 17531815: Crown, Military and Society (1986) estableció lo que son sus dos aportaciones clave. Por un lado, las reformas borbónicas entendidas como soluciones para mejorar militarmente a España. Por otro lado, el impacto de esas reformas en el mundo colonial, atendiendo a cómo reaccionaron los grupos de intereses locales. En cuanto a Kenneth J. Andrien, profesor de la Southern Methodist University (Dallas, TX), su ámbito de investigación, en obras como Crisis and Decline: The Viceroyalty of Peru in the Seventeenth Century (1985) o Andean Worlds: Indigenous History, Culture, and Consciousness under Spanish Rule, 1532-1825 (2001), ha sido el mundo andino colonial. En los últimos años ha extendido sus investigaciones de Latinoamérica en el mundo atlántico.

Como hemos mencionado anteriormente, ambos autores provienen de un paradigma interpretativo, como es el atlantismo, que lleva décadas en funcionamiento pero que en España ha sido introducido más recientemente. Desde los 50, en el contexto de la Guerra Fría, con el entendimiento del Atlántico como comunidad hasta el modelo de dependencia del marxismo, se ha querido destacar la importancia de las relaciones y conexiones entre Europa, América e incluso África. Un punto de inflexión lo supuso el trabajo de J. H. Elliott y su Los Imperios del Mundo Atlántico: Gran Bretaña y España en América (2006) ya que en lugar de hablar de una relación unidireccional, siempre en beneficio de la metrópolis, trató de demostrar no sólo las profundas conexiones económicas sino en muchos planos (cultural, discurso político...). Elliott trató de mostrar cómo los imperios español y británico fueron mutando a lo largo del tiempo, no únicamente por 
las nuevas políticas de la metrópoli sino, fundamentalmente, por la adquisición de una especie de mayoría de edad de las colonias. Su ganancia en autonomía como sociedad llevó a la conclusión que fueron las independencias.

Este marco explicativo es el que asumen Kuethe y Andrien en este trabajo. Es un contexto general, europeo y americano, y que explica las relaciones ente colonias y metrópolis tanto en sus interconexiones como en sus conflictos. El imperio se entiende como un proceso histórico.

El ámbito cronológico elegido es el siglo XVIII en el contexto de la llegada de una nueva dinastía al trono español (1713-1796). A partir de Felipe $V$ se construye un nuevo modelo de Estado, centralizado frente a la monarquía compuesta de los Austrias. El espacio es todo el imperio español, tanto en la península como en ultramar. Y como relato principal se narra cómo guerra y reforma se van entrelazando a lo largo del siglo. Las reformas borbónicas en relación al imperio no responden a un plan predeterminado sino al deseo de fortalecer militarmente al Estado y en sucesivas fases, con los conflictos del siglo como telón de fondo.

La utilización de archivos españoles, americanos y franceses, más un abundante repertorio de fuentes secundarias, donde las últimas publicaciones españoles juegan un papel importante, da a la obra el tono riguroso indispensable y ayuda a aportar más datos. Un buen ejemplo es la política colonial durante Felipe V. Los autores hablan de la escasez de datos procedentes de los archivos españoles lo que llevó a la historiografía tradicional a minusvalorar el reinado en cuanto a política reformista imperial se refiere. La utilización de documentación diplomática francesa ha ayudado a reconstruir mejor este período y así lo afirman Kuethe y Andrien. Por lo tanto, estamos ante una obra de pretensiones globalistas tanto en el relato como en las fuentes utilizadas para su escritura.

El libro tiene tres partes diferenciadas, más antes de entrar en ellas haremos referencia a su introducción. En ella se resume el proceso histórico central, la relación entre guerra y reforma, así como la posición teórica de partida de los autores. En cuanto a lo primero, se destaca la herencia de Utrecht por la cual el imperio americano se convertía en la principal posesión que España conservaba tras la Guerra de Sucesión. Esto hará que los sucesivos gobiernos y no sólo el de Carlos III, como tradicionalmente se había destacado, sean conscientes de la necesidad de mejorar las defensas y la obtención de recursos de las posesiones coloniales. La corriente atlantista es la que enmarca la obra y los autores se posicionan claramente en ella. Por lo tanto, el relato no es únicamente el conjunto de reformas impulsadas desde Madrid sino como un conjunto de intereses políticos, a veces partidarios y otras veces contrarios al reformismo. En la narración están presentes todos los protagonistas.

La primera parte abarca desde 1713 hasta 1736, con el reinado de Felipe V como paisaje de fondo. En este período hay dos protagonistas claros: Alberoni y su colaborador José Patiño. De esta parte, tres son las cuestiones a subrayar. En primer lugar, la conciencia clara y desde un principio de la necesidad de reformar las estructuras coloniales. Por lo tanto, desde el asentamiento definitivo de la dinastía se hace patente esta línea de actuación y no será abandonada durante 
el siglo. Los problemas eran más que patentes: contrabando, corrupción y falta de ingresos. Por otro lado, en este capítulo se pone de manifiesto otra cuestión clave que es la presencia de numerosos intereses, nacionales e internacionales, en América. En segundo lugar, las líneas maestras de las reformas posteriores se ponen en estas fechas (mejora de las defensas, obtención de mayores ingresos y alejamiento de potencias extranjeras). Destacable es la labor de Patiño para afianzar la secretaría de marina e indias, creando toda una estructura administrativa y de hombres capaz de aplicar las reformas. Será su legado para futuros momentos. En tercer lugar, otra clave establecida en este período fue como las preocupaciones dinásticas en Europa distrajeron muchas veces la política con respecto a América. Las reformas triunfaron únicamente cuando la política real puso todos sus esfuerzos en ello.

La segunda parte (1736-1763) tiene la política ensenadista, con algunos precedentes, como eje central. El triunfo político de Ensenada significó retomar el reformismo colonial, puesto que toda su política naval y de mejora de los recursos del Estado tenía por objetivo preservar el imperio. La guerra de la Oreja de Jenkins, a finales del reinado de Felipe $V$, puso de manifiesto que Gran Bretaña era el enemigo principal del imperio. La mejora de la flota y las defensas coloniales eran fundamentales para alejar a los británicos del escenario americano. A ello también se sumó la búsqueda de neutralidad, con ella conseguir recursos sería más fácil. En esta época, el Atlántico se consolidad como punto central de la política reformista. La herencia de Utrecht y los conflictos en Europa parecían alejarse. Pero de nuevo aparecen otros intereses, los británicos eran conscientes del impulso reformista de Ensenada, dinamitar la política de aquel entonces era estratégico para ellos. Se sumó una reacción contra Ensenada en la propia España. La coalición de intereses quito de la escena a Ensenada pero también a su política. La política neutralista, los intereses privados en las colonias y los nuevos grupos de poder alejaron las reformas hasta la pérdida de La Habana.

De nuevo, en la tercera parte (1763-1796), volvemos a ver como una muestra de debilidad militar mostró al Gobierno español la necesidad de aplicar medidas para solventar las debilidades del imperio. Durante el reinado de Carlos III se da un impulso a las medidas reformistas, con tres momentos. El primer momento, desde la pérdida de La Habana en 1762 y el Motín de Esquilache cuatro años después, destaca por la continuación del proyecto ensenadista: mejora de la flota, mayor control sobre las colonias con la figura del visitador y construcción de defensas en el ámbito caribeño. Este último aspecto puede ser el más importante al menos en cuanto a la toma de conciencia de que el Caribe era la parte central del imperio porque en él entraban todas las potencias y es donde las ganancias eran menos dependientes de los metales preciosos sino de la modernización comercial con las plantaciones. La aplicación de las reformas no va a ser un asunto fácil, la caída de Esquilache demostró que había otros grupos de intereses y ya había habido problemas en las mismas colonias. En este momento entramos en el segundo momento reformista, porque la subida al poder de otro grupo político no supone una paralización de las reformas como había sucedido en otros mo- 
mentos sino todo lo contrario. La ascensión de Floridablanca, tras sus gestiones con respecto a la Expulsión de los jesuitas, y de personajes como José de Gálvez Ilevan la reforma a sus cotas más altas. La victoria sobre Gran Bretaña, durante la Guerra de Independencia norteamericana, va a ser el mayor éxito de una política reformista encaminada a ganar guerras. Porque esa es la gran herencia para el tercer momento, que coincide con los últimos años de Carlos III y los primeros de su hijo Carlos IV. Las reformas para ganar guerras no permitieron modernizar la economía, al menos para beneficio de la metrópoli. Las colonias sí salieron ganando con la liberalización del comercio y la creación de defensas propias. Todo se gastó en ellas y para ellas, junto a la flota. Las deudas contraídas si dieron remesas a España. Pero ¿qué pasaría cuando el comercio se cortara? El dinero se quedaría en América pero no en España. Algo peligroso si como en 1796 se entraba en guerra con Europa. Dicha guerra no sólo fue una derrota militar sino un mar de deudas que sepultaron al Estado que ya no pudo mejorar la flota y ni siquiera reconstruyó los barcos perdidos.

Este último punto puede que quizás sea la aportación más original, al menos desde el punto de los acontecimientos siendo en general casi todos ya conocidos. La herencia de la victoria en la independencia norteamericana va a ser pesadas. Las deudas se sostienen mientras en Europa no hubo problemas pero en cuanto estalló la Revolución francesa todo se va al traste. Todos los costes y esfuerzos desde Ensenada se habían puesto en América y ahora se perdían porque España no podía acceder a ellos. Peleaba en Europa pero no podía acceder a los recursos coloniales. La reforma fracasa porque no beneficia al Estado y el Estado, en estos momentos, es Madrid. Eso sí, a los coloniales, a pesar de tanta protesta, les vino finalmente bien. Contaban con sus propios recursos y unas estructuras modernizadas. Habían ganado independencia.

La otra aportación interesante del libro tiene que ver con la mención constante a los diversos y casi siempre contradictorios intereses puestos sobre el tablero del imperio. Los políticos del rey buscaban una cosa, las elites coloniales otras y siempre todo bajo la atenta mirada de las otras potencias imperiales. El relato va alternando períodos reformistas con períodos de paralización, todo dependiendo de quién tenía más fuerza en ese momento. El punto está en dejar de ver la política colonial de los Borbones como una imposición desde arriba, premeditada y concesión en la práctica del ilustrado Carlos III. La política colonial fue siempre circunstancial, para ganar guerras, no uniforme y en la mesa del rey desde tiempos de Felipe V. Fue una suma de voluntades concretas y siempre que éstas tuvieran la fuerza para aplicarlas.

Quizás el punto menos aclarado en este trabajo sea precisamente el de cómo se pudo aplicar. Sí se habla de remesas y metales, de grandes ministros reformistas o de la buena voluntad de los reyes. En cambio, se habla poco de cómo se utilizaron esos recursos. Las flotas parecen construirse solas. ¿Quiénes fueron esos mandos intermedios y locales que aplicaron lo dictado desde Madrid? ¿Quiénes eran en América los interesados en las reformas? En definitiva, las estructuras creadas para permitir que del papel se pasara al hecho. Por eso cuando se men- 
ciona la labor de Patiño en crear una estructura funcionarial es cuando podemos vislumbrar mejor los medios pero por desgracia no se ahonda lo suficiente. Aun así estamos ante una narración bastante completa de la política reformista en el imperio español: de sus fines, causas y consecuencias. La gran virtud de los autores es reconstruir el proceso global situando al Atlántico como uno de los principales ejes de la política del XVIII.

Roberto Pastor Universidad de La Rioja 